Check for updates

Cite this: RSC Adv., 2017, 7, 46125

Received 25th July 2017

Accepted 6th September 2017

DOI: $10.1039 / c 7 r a 08188 j$

rsc.li/rsc-advances

\title{
Solvent-induced diversity of luminescent metal- organic frameworks based on different secondary building units $\uparrow$
}

\begin{abstract}
Lu Wang, Guo-Ping Yang, (D) Yang-Tian Yan, Jing Jin, Yan Ning and Yao-Yu Wang
By using a symmetrical $V$-shaped rigid $5^{\prime}$-carboxyl- $\left(1,1^{\prime}-3^{\prime}, 1^{\prime \prime}\right.$-terphenyl)-4,4" -dicarboxylic acid $\left(\mathrm{H}_{3} \mathrm{~L}\right)$, three $\mathrm{Cd}(I)$-based metal-organic frameworks (MOFs), $\left[\mathrm{Cd}_{3}(\mathrm{~L})_{2}\left(\mathrm{H}_{2} \mathrm{O}\right)_{4}\right] \cdot \mathrm{DMF}(1),\left[\mathrm{Cd}_{2}(\mathrm{~L})\left(\mathrm{SO}_{4}\right)_{2}\right] \cdot 3(\mathrm{Me})_{2} \mathrm{NH}_{2}(2)$ and $\left[\mathrm{Cd}(\mathrm{HL})\left(\mathrm{H}_{2} \mathrm{O}\right)\right] \cdot 0.5 \mathrm{H}_{2} \mathrm{O}(3)$, have been synthesized under solvothermal conditions. Due to the reactions in different solvent systems, $\mathrm{L}^{3-} / \mathrm{HL}^{2-}$ in 1-3 show different coordination modes with $\mathrm{Cd}(\Perp)$ ions to form various secondary building units (SBUs) in the final structures. The desolvated structure of 1 (1a) contains two shapes of 1D channels with suitable pore sizes. 2 is a 3D dense packing pattern with a three nodal $(5,6,7)$-connected new topological net, and 3 is a 2D layered $(4,4)$-connected sql network connected with partly deprotonated $\mathrm{HL}^{2-}$ ligands. As a result, 1a possesses not only high $\mathrm{CO}_{2}$ loading but also excellent $\mathrm{CO}_{2} / \mathrm{CH}_{4}$ selectivity. In addition, all complexes display solid-state luminescence stemming from ligand-to-metal charge transfer.
\end{abstract}

\section{Introduction}

Metal-organic frameworks (MOFs) ${ }^{1}$ are porous materials showing a wide variety of thrilling chemical and physical properties, and, consequently, can be explored as functional materials in very diverse fields. ${ }^{2}$ Indeed, both the porosity of MOFs and their fascinating host-guest chemistry lie at the origin of most of these properties. ${ }^{3}$ Similar to other porous materials, ${ }^{4}$ MOFs have proven their efficiency as vessels to capture and host small molecules, and, eventually, to separate mixtures of molecules according to their steric and stereochemical features as well as reactivity properties (functional substituent groups). ${ }^{5}$ Anthropogenic carbon dioxide emissions to the atmosphere are one of the most urgent climate issues of our age, which makes the development of materials for capturing the carbon dioxide produced by fossil fuels and sequestering it away from the atmosphere one of the grand challenges of the 21st century. ${ }^{6}$ Owing to MOFs diversity and performance, hierarchically porous structures have attracted considerable attention as an important family of functional materials in recent years. ${ }^{7}$

As the basic building blocks, the organic ligands are vital in the assembly of structures and functions of MOFs. The rigid

Key Laboratory of Synthetic and Natural Functional Molecule Chemistry of the Ministry of Education, Shaanxi Key Laboratory of Physico-Inorganic Chemistry, College of Chemistry \& Materials Science, Northwest University, Xi'an 710127, P. R. China. E-mail: ygp@nwu.edu.cn

$\dagger$ Electronic supplementary information (ESI) available: Some figures of single-crystals, PXRD, IR, TGA, selected bond length/angle tables. CCDC 1561956-1561958. For ESI and crystallographic data in CIF or other electronic format see DOI: $10.1039 / \mathrm{c} 7 \mathrm{ra} 08188 \mathrm{j}$ aromatic multicarboxylate ligands have been proved to be the ideal candidates for building versatile MOFs with rigidity, porosity, thermal and chemical stabilities, ${ }^{8}$ such as $1,3,5$-benzenetricarboxylate, 1,2,4,5-benzenetetracarboxylate, and 4,4'biphenyldicarboxylate. ${ }^{9}$ With a more in-depth study, the Vshaped rigid multicarboxylate ligands show plentiful advantages due to their manifold coordination modes, and they are liable to form cluster-based secondary building units (SBUs) with various metal ions. ${ }^{10}$ In many instances, a V-shaped steric configuration is favourable to form versatile high-dimensional and porous frameworks. ${ }^{11}$ Up to now, there are many porous MOFs assembled by utilizing V-shaped rigid multicarboxylates ${ }^{12}$ such as 3,5-di(3,5-dicarboxylpheny)benzoic acid, 3,3',5,5'-benzene-1,3-biyl-tetra-benzoic acid, and so on, which possess fascinating structures as well as intriguing properties.

In this work, a symmetrical $\mathrm{V}$-shaped rigid ligand, $5^{\prime}$ carboxyl-( $\left(1,1^{\prime}-3^{\prime}, 1^{\prime \prime}\right.$-terphenyl)-4, $4^{\prime \prime}$-dicarboxylic acid $\left(\mathrm{H}_{3} \mathrm{~L}\right)$ (Scheme 1), is chosen to fabricate porous MOFs based on the following advantages: (i) $\mathrm{H}_{3} \mathrm{~L}$ with three carboxylic groups possesses multiple coordination sites and various coordination modes, which is beneficial to produce porous frameworks; (ii)<smiles>O=C(O)c1ccc(-c2cc(C(=O)O)cc(-c3ccc(C(=O)O)cc3)c2)cc1</smiles>

Scheme $1 \quad 5^{\prime}$-Carboxyl-(1,1'-3', $1^{\prime \prime}$-terphenyl)-4,4" -dicarboxylic acid. 
the multicarboxylic groups in $\mathrm{H}_{3} \mathrm{~L}$ has an inclination to form various metal clusters, which can not only stabilize the structure, but also accelerate the interactions between the framework and $\mathrm{CO}_{2} \cdot{ }^{13}$ Herein, the reaction of $\mathrm{H}_{3} \mathrm{~L}$ with $\mathrm{Cd}(\mathrm{II})$ ions gave three new luminescent MOFs, $\left[\mathrm{Cd}_{3}(\mathrm{~L})_{2}\left(\mathrm{H}_{2} \mathrm{O}\right)_{4}\right] \cdot \mathrm{DMF}$ (1), $\left[\mathrm{Cd}_{2}(\mathrm{~L})\left(\mathrm{SO}_{4}\right)_{2}\right] \cdot 3(\mathrm{Me})_{2} \mathrm{NH}_{2} \quad(2), \quad\left[\mathrm{Cd}(\mathrm{HL})\left(\mathrm{H}_{2} \mathrm{O}\right)\right] \cdot 0.5 \mathrm{H}_{2} \mathrm{O} \quad$ (3). $\mathrm{L}^{3-} / \mathrm{HL}^{2-}$ in 1-3 show different coordination modes and can easily form various SBUs in the final structures. Complexes 1-3 reveal the luminescent properties, as well as selective adsorption for $\mathrm{CO}_{2}$ over $\mathrm{CH}_{4}$ for 1 .

\section{Experimental section}

\subsection{Materials and general methods}

All the reagents and solvents were purchased from commercial sources and used directly without further purification. Elemental analyses (C, H, and N) were performed on PerkinElmer 2400C Elemental Analyzer. Infrared (IR) spectra were acquired with $\mathrm{KBr}$ discs in the range of 4000 to $400 \mathrm{~cm}^{-1}$ on Bruker EQUINOX-55 IR spectrometer. Thermogravimetric analyses (TGA) were collected on NETZSCH STA 449C microanalyzer under $\mathrm{N}_{2}$ stream at a heating rate of $5{ }^{\circ} \mathrm{C} \mathrm{min}^{-1}$. Powder X-ray diffraction patterns were collected on a Bruker D8 ADVANCE X-ray powder diffractometer (Cu K $\alpha, 1.5418 \AA)$ at room temperature. Gas sorption isotherms were measured by ASAP $2020 \mathrm{M}$ adsorption equipment. The solid state luminescent spectra were collected on a Hitachi F-4500 fluorescence spectrophotometer at room temperature.

\subsection{Synthesis of $\left[\mathrm{Cd}_{3}(\mathrm{~L})_{2}\left(\mathrm{H}_{2} \mathrm{O}\right)_{4}\right] \cdot \mathrm{DMF}(1)$}

A mixture of $\mathrm{Cd}\left(\mathrm{NO}_{3}\right)_{2} \cdot 4 \mathrm{H}_{2} \mathrm{O}(0.0308 \mathrm{~g}, 0.1 \mathrm{mmol}), \mathrm{H}_{3} \mathrm{~L}(0.018 \mathrm{~g}$, $0.05 \mathrm{mmol})$ and $\mathrm{DMF} / \mathrm{H}_{2} \mathrm{O}(15.0 \mathrm{~mL}, \mathrm{v} / \mathrm{v}=1 / 1)(\mathrm{DMF}=N, N-$ dimethylformamide) was mixed in a Teflon-lined stainless steel vessel $(25 \mathrm{~mL})$, and then heated at $150{ }^{\circ} \mathrm{C}$ for $72 \mathrm{~h}$. After a gradual cooling procedure to room temperature, colourless block crystals were obtained in $\sim 51.3 \%$ yield based on $\mathrm{Cd}$. Anal. calcd for $\mathrm{C}_{45} \mathrm{H}_{37} \mathrm{Cd}_{3} \mathrm{NO}_{17}$ : C, 45.0; $\mathrm{H}, 3.08 ; \mathrm{N}, 1.17$. Found: $\mathrm{C}$, 45.52; H, 3.17; N, 1.72\%. IR ( $\left.\mathrm{cm}^{-1}\right): 3423(\mathrm{w}), 3235$ (w), $2923(\mathrm{~m})$, 1652 (s), 1521 (s), 1313 (m), 1182 (w), 1103 (w), 862 (w), 767 (m), $609(\mathrm{w})$.

\subsection{Synthesis of $\left[\mathrm{Cd}_{2}(\mathrm{~L})\left(\mathrm{SO}_{4}\right)_{2}\right] \cdot 3(\mathrm{Me})_{2} \mathrm{NH}_{2}(2)$}

A mixture of $\mathrm{Cd}\left(\mathrm{NO}_{3}\right)_{2} \cdot 4 \mathrm{H}_{2} \mathrm{O}(0.0308 \mathrm{~g}, 0.1 \mathrm{mmol}), \mathrm{H}_{3} \mathrm{~L}(0.018 \mathrm{~g}$, $0.05 \mathrm{mmol}), \mathrm{DMF} /$ ETOH $(15.0 \mathrm{~mL}, \mathrm{v} / \mathrm{v}=4 / 1)$ and $\mathrm{H}_{2} \mathrm{SO}_{4}: \mathrm{H}_{2} \mathrm{O}$ $(1: 3)$ was mixed in a Teflon-lined stainless steel vessel $(25 \mathrm{~mL})$, and then heated at $120{ }^{\circ} \mathrm{C}$ for $72 \mathrm{~h}$. After a gradual cooling procedure to room temperature, colourless block crystals were obtained in $\sim 49.0 \%$ yield based on Cd. Anal. calcd for $\mathrm{C}_{27} \mathrm{H}_{35^{-}}$ $\mathrm{Cd}_{2} \mathrm{~N}_{3} \mathrm{O}_{14} \mathrm{~S}_{2}$ : C, 35.45; H, 3.83; N, 4.6. Found: C, 34.53; H, 3.17; N, 4.3\%. IR (cm ${ }^{-1}$ ): 3438 (m), 3027 (s), 2794 (s), 2478 (s), 1594 (s), 1548 (s), 1394 (s), 1106 (s), 1031 (s), 960 (m), 856 (m), 767 (m), $609(\mathrm{~m})$.

\subsection{Synthesis of $\left[\mathrm{Cd}(\mathrm{HL})\left(\mathrm{H}_{2} \mathrm{O}\right)\right] \cdot 0.5 \mathrm{H}_{2} \mathrm{O}(3)$}

A mixture of $\mathrm{Cd}\left(\mathrm{NO}_{3}\right)_{2} \cdot 4 \mathrm{H}_{2} \mathrm{O}(0.0308 \mathrm{~g}, 0.1 \mathrm{mmol}), \mathrm{H}_{3} \mathrm{~L}(0.018 \mathrm{~g}$, $0.05 \mathrm{mmol})$ and $\mathrm{H}_{2} \mathrm{O} / \mathrm{CH}_{3} \mathrm{CN}(14.0 \mathrm{~mL}, \mathrm{v} / \mathrm{v}=2 / 5)$ was mixed in
Table 1 Crystallographic data of 1-3

\begin{tabular}{|c|c|c|c|}
\hline Complex & 1 & 2 & 3 \\
\hline Formula & $\mathrm{C}_{44} \mathrm{H}_{31} \mathrm{Cd}_{2} \mathrm{NO}_{14}$ & $\mathrm{C}_{27} \mathrm{H}_{35} \mathrm{Cd}_{2} \mathrm{~N}_{3} \mathrm{O}_{14} \mathrm{~S}_{2}$ & $\mathrm{C}_{23} \mathrm{H}_{18} \mathrm{CdO}_{7.5}$ \\
\hline$M_{\mathrm{r}}$ & 1200 & 914.52 & 499 \\
\hline Crystal system & Monoclinic & Monoclinic & Triclinic \\
\hline Space group & $C 2 / c$ & $C 2 / c$ & $P \overline{1}$ \\
\hline$a(\AA)$ & 36.916 & 17.442 & 7.079 \\
\hline$b(\AA)$ & 21.399 & 21.243 & 11.288 \\
\hline$c(\AA)$ & 7.2173 & 11.468 & 13.130 \\
\hline$\alpha\left(^{\circ}\right)$ & 90 & 90 & 65.420 \\
\hline$\beta\left(^{\circ}\right)$ & 98.129 & 129.716 & 83.016 \\
\hline$\gamma\left({ }^{\circ}\right)$ & 90 & 90 & 85.505 \\
\hline$V\left(\AA^{3}\right)$ & 5644.1 & 3269 & 946.6 \\
\hline$Z$ & 4 & 4 & 2 \\
\hline$D_{\text {calc }}\left(\mathrm{g} \mathrm{cm}^{-3}\right)$ & 1.327 & 1.858 & 1.722 \\
\hline$F(000)$ & 2216 & 1832 & 488 \\
\hline$R_{\text {int }}$ & 0.0453 & 0.0715 & 0.0243 \\
\hline GOF on $F^{2}$ & 1.008 & 1.244 & 1.339 \\
\hline$R_{1}^{a}[I>2 \sigma(I)]$ & 0.0580 & 0.0796 & 0.0744 \\
\hline $\mathrm{w} R_{2}^{b}$ (all data) & 0.2294 & 0.3130 & 0.2995 \\
\hline
\end{tabular}

a Teflon-lined stainless steel vessel $(25 \mathrm{~mL})$, and then heated at $105{ }^{\circ} \mathrm{C}$ for $72 \mathrm{~h}$. After a gradual cooling procedure to room temperature, colourless block crystals were obtained in $\sim 49.7 \%$ yield based on $\mathrm{Cd}$. Anal. calcd for $\mathrm{C}_{23} \mathrm{H}_{18} \mathrm{CdO}_{7.5}$ : C, 64.97; $\mathrm{H}$, 3.20. Found: C, 64.52; H, 3.6. IR ( $\left.\mathrm{cm}^{-1}\right): 3436$ (m), 2931 (s), 2794 (s), 1664 (m), 1608 (m), 1405 (s), 1265 (m), 1031 (s), 1110 (m), $935(\mathrm{w}), 858(\mathrm{w}), 769(\mathrm{~m})$.

\subsection{Crystallographic data collection and refinement}

Suitable single crystals were tested using a Bruker SMART APEXII CCD diffractometer equipped with Mo-K $\alpha$ radiation $(\lambda=$ $0.71073 \AA$ ) at room temperature. The structures were solved using direct methods and refined using a full-matrix leastsquares refinement on $F^{2}$ with SHELXL-2014 and olex2. ${ }^{14}$ Nonhydrogen atoms were refined with anisotropic displacement parameters. The solvent molecules in $\mathbf{1}$ and $\mathbf{3}$ were highly disordered and were removed from the diffraction data by using the SQUEEZE routine of PLATON. ${ }^{15}$ The final formulae of $\mathbf{1}$ and 3 were determined by single-crystal structures, elemental analysis results and TGA. The relevant crystallographic data are shown in Table 1 . Selected bond lengths and angles are listed in Table S1 (ESI $\dagger$ ). CCDC numbers are 1561956-1561958 for 1-3, respectively.

\section{Results and discussion}

\subsection{Crystal structure of $\left[\mathrm{Cd}_{3}(\mathrm{~L})_{2}\left(\mathrm{H}_{2} \mathrm{O}\right)_{4}\right] \cdot \mathrm{DMF}(1)$}

Compound 1 crystallizes in the monoclinic space group $C 2 / c$. As shown in the Fig. 1, the asymmetric unit consists of one and a half $\mathrm{Cd}(\mathrm{II})$ ions, one fully deprotonated $\mathrm{L}^{3-}$ ligand, five coordinated $\mathrm{H}_{2} \mathrm{O}$ molecules, and one free DMF molecules. $\mathrm{Cd} 1$ is seven connected by $\mathrm{O}$ atoms from four $\mathrm{L}^{3-}$ ligand and one $\mathrm{H}_{2} \mathrm{O}$ molecules. Different from that of $\mathrm{Cd} 1, \mathrm{Cd} 2$ is six connected by $\mathrm{O}$ atoms from two axial $\mathrm{L}^{3-}$ ligand and two equatorial $\mathrm{H}_{2} \mathrm{O}$ 


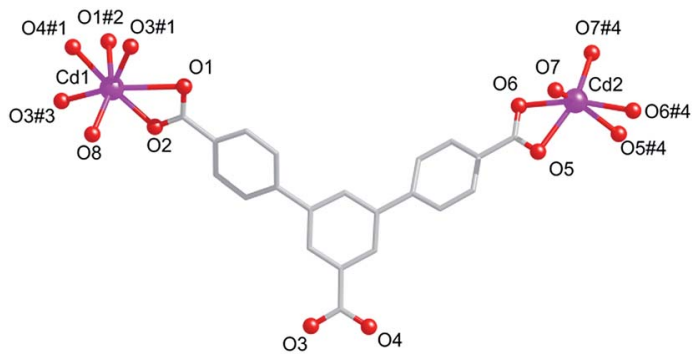

Fig. 1 Coordination environment around the $\mathrm{Cd}(\mathrm{I})$ ions in 1 . Symmetry codes: \#1: $1.5-x, 0.5+y, 2.5-z$, \#2: $x, 2-y, 0.5+z, \# 3: 1.5-x, 1.5-$ $y, 3-z$. \#4: $1-x, y,-0.5-z$.

molecules. The Cd-O distances vary from 2.241(12) to 2.62(3) $\mathrm{A}$, and the $\mathrm{O}-\mathrm{Cd}-\mathrm{O}$ angles are in the range from $53.37^{\circ}$ to $167.28^{\circ}$.

In $1, \mathrm{Cd} 1$ ions take coordination with carboxylates of $\mathrm{L}^{3-}$ ligands to form 1D rod-shaped SBUs (Fig. 2a). Then these 1D SBUs are further extended by the $\mathrm{Cd} 2$ ions and $\mathrm{L}^{3-}$ linkers together to give rise to a 3D porous framework (Fig. 2b). There exist two types of 1D open channels with different shapes along $c$ axis with the effective aperture sizes of $18.1 \times 16.2 \AA^{2}$ and $10.2 \times$ $8.4 \AA^{2}$, respectively, where the free solvent DMF molecules are located. After the hypothetical removal of the noncoordinated and disordered solvent molecules, the potential solvent area volume of $1 \mathrm{a}-\left[\mathrm{Cd}_{3}(\mathrm{~L})_{2}\left(\mathrm{H}_{2} \mathrm{O}\right)_{4}\right]$ is determined to be $\sim 36.5 \%$ out of the total volume by the PLATON program. Topologically, $\mathrm{L}^{3-}$ and the $\mathrm{Cd} 1$ ions can be considered as five, four-connected nodes, respectively. Thus, the framework of $\mathbf{1}$ can be view as a $(4,5)$ connected tes net with the point symbol of $\left(4^{4} \cdot 6^{2}\right)\left(4^{4} \cdot 6^{6}\right)$ (Fig. 2c).

\subsection{Crystal structure of $\left[\mathrm{Cd}_{2}(\mathrm{~L})\left(\mathrm{SO}_{4}\right)_{2}\right] \cdot 3(\mathrm{Me})_{2} \mathrm{NH}_{2}(2)$}

Compound 2 is a $3 \mathrm{D}$ framework crystallizing in the monoclinic space group $C 2 / c$. The asymmetric unit contains two independent $\mathrm{Cd}(\mathrm{II})$ ions, one $\mathrm{L}^{3-}$ ligand, two coordinated sulphate anions, and three dimethylammonium cations. The $\mathrm{Cd} 1$ and $\mathrm{Cd} 2$ display the distorted hexahedral pyramidal coordination geometries (Fig. 3). Cd1 is six-coordinate and anchored by four carboxylate groups from four different $\mathrm{L}^{3-}$ and two coordinated sulfate anions. $\mathrm{Cd} 2$ is also six-coordinated, and anchored by four carboxylate groups

(a)

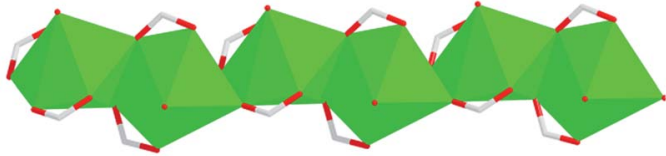

(b)
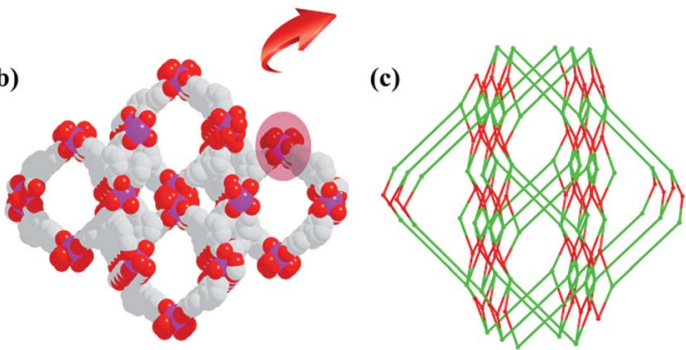

Fig. 2 (a) The 1D rod-shaped SBU in 1. (b) The 3D microporous framework of 1. (c) The $(4,5)$-connected topology network.

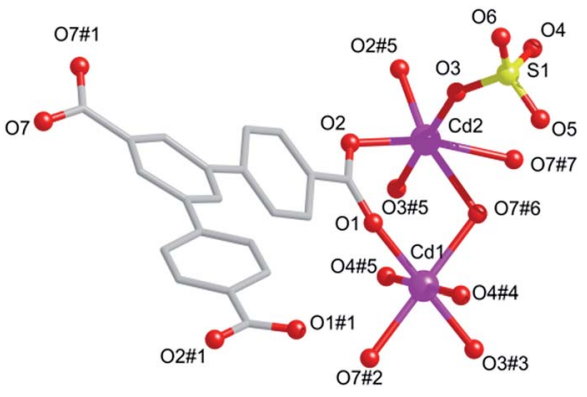

Fig. 3 Coordination environment around the $\mathrm{Cd}(\Perp)$ ions in 2 . Symmetry codes: \#1: $2-x, y, 1.5-z, \# 2: 2-x, 1-y, 2-z, \# 3: 1.5-x$, $0.5-y, 2-z, \# 4: 0.5+x, 0.5-y, 0.5+z, \# 5: 1-x, y, 1.5-z, \# 6:-0.5$ $+x,-0.5+y, z, \# 7: 1.5-x,-0.5+y, 1.5-z$.

from four different ligands and two coordinated sulfate anions. The Cd-O distances vary from $2.446(6)$ to $2.194(8) \AA$, and the O$\mathrm{Cd}-\mathrm{O}$ angles are in the range from $53.5(3)^{\circ}$ to $180.0^{\circ}$.

Similar to that of $\mathbf{1}$, an infinite $1 \mathrm{D}$ rod-shaped SBU chain is formed by the carboxylate of $\mathrm{L}^{3-}$ and sulfate with $\mathrm{Cd}(\mathrm{II})$ ions in 2 (Fig. 4a). These 1D SBUs based on Cd1 and Cd2 are further extended by the organic linker to a 3D porous network, where the dimethylammonium cations and sulfate are included (Fig. 4b). Topologically, the linkers can be viewed as sevenconnected nodes, and the centre metal ions (Cd1 and $\mathrm{Cd} 2$ ) can act as 5,6-connected nodes, respectively. Thus, the structure of 2 can be simplified as a 3-nodal $(5,6,7)$-connected new topological net with a point symbol of $\left(3^{4} \cdot 4^{3} \cdot 5^{2} \cdot 6\right)\left(3^{4} \cdot 4^{3} \cdot 5^{4} \cdot 6^{10}\right)\left(3^{4} \cdot 4^{4} \cdot 5^{4} \cdot 6^{3}\right)$ (Fig. $\left.4 \mathrm{c}\right)$.

\subsection{Crystal structure of $\left[\mathrm{Cd}(\mathrm{HL})\left(\mathrm{H}_{2} \mathrm{O}\right)\right] \cdot 0.5 \mathrm{H}_{2} \mathrm{O}(3)$}

Compound 3 crystallizes in the triclinic space group $P \overline{1}$. The asymmetric building unit of 3 contains one Cd(II) center, one partly deprotonated $\mathrm{HL}^{2-}$ ligand, one coordination water molecule, and a half free water molecule. Each centre $\mathrm{Cd}(\mathrm{II})$ is surrounded by six oxygen atoms from four different carboxylate groups of four $\mathrm{HL}^{2-}$ ligands and one water molecule (Fig. 5). The lengths of Cd-O bonds are in the range of 2.375(7)-2.194(8) A.

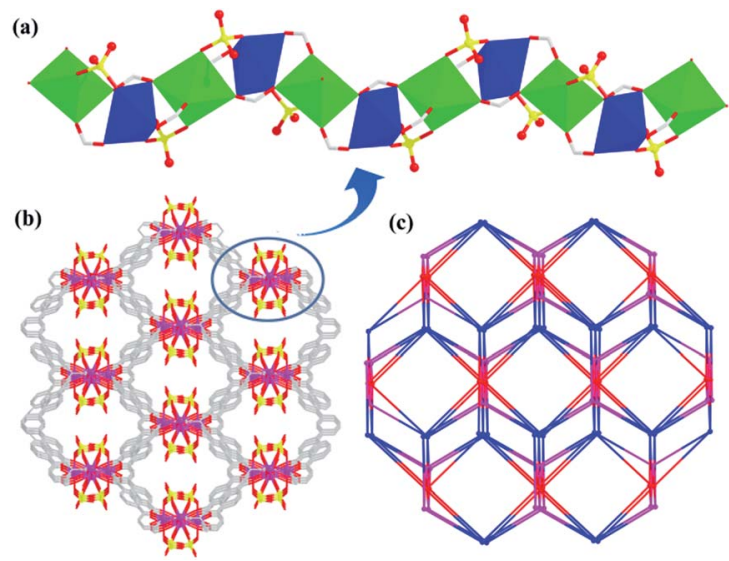

Fig. 4 (a) The 1D chain SBU in 2. (b) The 3D framework of 2. (c) $(5,6,7)$ connected topological network. 
Due to the existence of deprotonated $\mathrm{HL}^{2-}$ ligand in 3 , a dimeric SBU is only formed by the carboxylate of $\mathrm{HL}^{2-}$ ligands and Cd(II) ions (Fig. S1a, ESI $\dagger$ ). The dimeric units are bridged by the linkers to yield a 2D layer (Fig. 6a). Both the linkers and the centre Cd(II) can be viewed as four-coordinated nodes, and the framework forms an uninodal $(4,4)$-connected sql topology with the point symbol of $\left(4^{4} \cdot 6^{2}\right)$ (Fig. 6b). Further, these 2D layers further are stacked together via hydrogen bonding $\mathrm{O} 7-\mathrm{H} 7 \mathrm{~B} \cdots$ $\mathrm{O} 2$ and $\mathrm{O} 7-\mathrm{H} 7 \mathrm{~A} \cdots \mathrm{O} 3$ to construct a 3D supramolecular framework (Fig. S1b, ESI $\dagger$ ).

\subsection{Coordination modes of $\mathrm{H}_{3} \mathrm{~L}$ ligand in complexes 1-3}

The comparative structural studies of 1-3 reveal that the coordination mode of $\mathrm{H}_{3} \mathrm{~L}$ is significantly influenced by the central metals and the solvent environment in the formation of frameworks. The $\mathrm{H}_{3} \mathrm{~L}$ in $\mathbf{1}$ and $\mathbf{2}$ is fully deprotonated, and connect six metal ions. In contrast, the $\mathrm{H}_{3} \mathrm{~L}$ in 3 is partly deprotonated, and connect four metal ions. As shown in Scheme 2, the three carboxylates of $\mathrm{L}^{3-}$ coordination fashions to connect with the centre $\mathrm{Cd}$ (II) ions. In 1, the three carboxylates of $\mathrm{L}^{3-}$ exhibit two different coordination modes: chelating bidentate $\left(\eta^{2} \mu_{1} \chi^{2}\right)$ and bridging tridentate $\left(\eta^{2} \mu_{2} \chi^{3}\right)$. In 2 , the three carboxylates of $\mathrm{L}^{3-}$ present two different coordination modes: bridging bidentate $\left(\eta^{2} \mu_{2} \chi^{2}\right)$ and bridging tetradentate $\left(\eta^{2} \mu_{3} \chi^{4}\right)$ modes. In 3 , the three carboxylates of $\mathrm{HL}^{2-}$ exhibit three different coordination modes: monodentate $\left(\eta^{1} \mu_{1} \chi^{1}\right)$ chelating monodentate $\left(\eta^{2} \mu_{1} \chi^{2}\right)$ and bridging bidentate $\left(\eta^{2} \mu_{2} \chi^{2}\right)$. The structures of $1-3$ suggest that not only $\mathrm{H}_{3} \mathrm{~L}$ coordinate with the different number of metal ions, the different coordination modes of carboxylates play an important role in determining the distinction of final structural topologies. In addition, the coordinated solvents also significantly influence the structures of the frameworks, that is, there is one coordinated $\mathrm{SO}_{4}{ }^{2-}$ anion in 2 and four $\mathrm{H}_{2} \mathrm{O}$ molecules in 1 . The difference of the coordination solvents affects the coordination environment of the central metals and coordination modes of ligands, leading to different structures.

\subsection{PXRD and thermal analyses}

The PXRD patterns show that the peak positions of the obtained crystalline samples of 1-3 match well with the simulated from

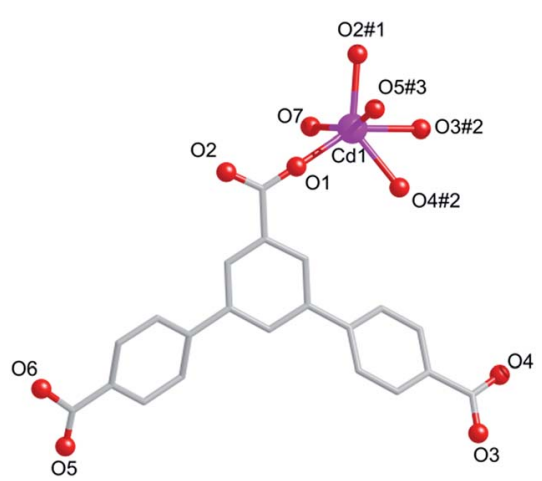

Fig. 5 Coordination environment of $\mathrm{Cd}(\mathrm{II})$ ions in 4 . Symmetry codes: \#1: $-x,-y,-z, \# 2:-1-x,-y, 1-z, \# 3:-1+x,-1+y, z$.
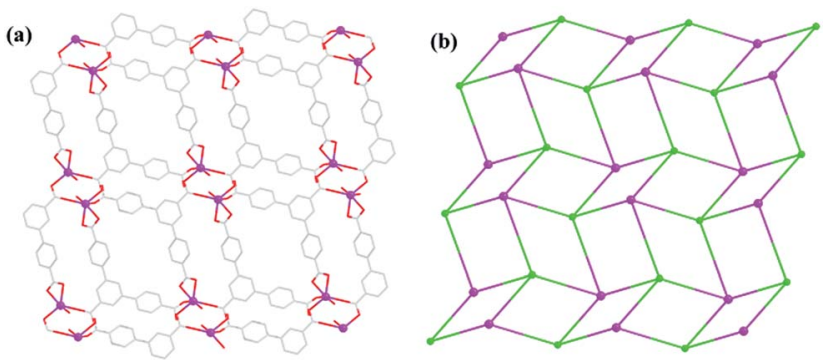

Fig. 6 (a) The 2D layer of 3. (b) The $(4,4)$-connected network.

the single-crystal data, manifesting the phase purity of the synthesized samples (Fig. S2, ESI $\dagger$ ). TGA on 1-3 were performed in a $\mathrm{N}_{2}$ atmosphere from 30 to $700{ }^{\circ} \mathrm{C}$ (Fig. S3, ESI $\dagger$ ). Complex 1 indicates a weight loss of $12.6 \%$ in the range of $30-130{ }^{\circ} \mathrm{C}$, which consists of the release of one DMF and four coordinated $\mathrm{H}_{2} \mathrm{O}$ molecule per formula unit (calcd 12.1\%). 2 released two coordinated $\mathrm{SO}_{4}{ }^{2-}$ anion and three $\mathrm{H}_{2} \mathrm{~N}(\mathrm{Me})_{2}$ cations between 30 and $375{ }^{\circ} \mathrm{C}$ with a weight loss of $36.6 \%$ (calcd $36.2 \%$ ). For 3, it lost one coordinated water and half lattice water molecule from 30 to $110{ }^{\circ} \mathrm{C}$ with a weight loss of $5.1 \%$ (calcd $5.5 \%$ ), and the major framework is stable up to $365{ }^{\circ} \mathrm{C}$ and then begins to collapse.

\subsection{Gas adsorption and discussion}

To obtain the guest-free phase of $\mathbf{1 a}, \mathbf{1}$ was soaked in $\mathrm{CH}_{2} \mathrm{Cl}_{2}$ for 7 days and subsequent heating at $150{ }^{\circ} \mathrm{C}$ under vacuum for $6 \mathrm{~h}$, which is evidenced by the TGA curve of 1a (Fig. S3a, ESI $\dagger$ ). The IR of 1a (Fig. S4, ESI $\dagger$ ) shows that the lack of characteristic $\mathrm{C}=\mathrm{O}$ vibration of DMF reveals that the disordered solvent has been removed from the nanotubes. The structure integrity of $\mathbf{1 a}$ has also been verified by the PXRD experiment (Fig. S2a, ESI $\dagger$ ).

To verify the porosity of 1a, the sorption isotherms of $\mathrm{N}_{2}$, $\mathrm{CO}_{2}$, and $\mathrm{CH}_{4}$ were measured at different temperatures. As shown in Fig. S6 (ESI $\dagger$ ), the lower $\mathrm{N}_{2}$ uptake $\left(28.69 \mathrm{~cm}^{3} \mathrm{~g}^{-1}\right)$ of $1 \mathrm{a}$ at $77 \mathrm{~K}$ and 1 bar may be due to the strong interactions of incoming guest molecules with the pore windows at $77 \mathrm{~K}$, which prevents the next incoming guest molecules from entering into the pore. ${ }^{16}$ On the basis of the $\mathrm{N}_{2}$ adsorption isotherm, the Brunauer-Emmett-Teller (BET) and Langmuir surface areas are $17.06 \mathrm{~m}^{2} \mathrm{~g}^{-1}$ and $26.22 \mathrm{~m}^{2} \mathrm{~g}^{-1}$, respectively. At $195 \mathrm{~K}, 1 \mathrm{a}$ exhibits the stepwise gas adsorption toward $\mathrm{CO}_{2}$ gas, and the second uptake occurs around $P /$ Torr $=300 \mathrm{mmHg}$, showing an uptake of $81.8 \mathrm{~cm}^{3} \mathrm{~g}^{-1}(16.67 \mathrm{wt} \%)$ which is more than that of the $\mathrm{CH}_{4}$

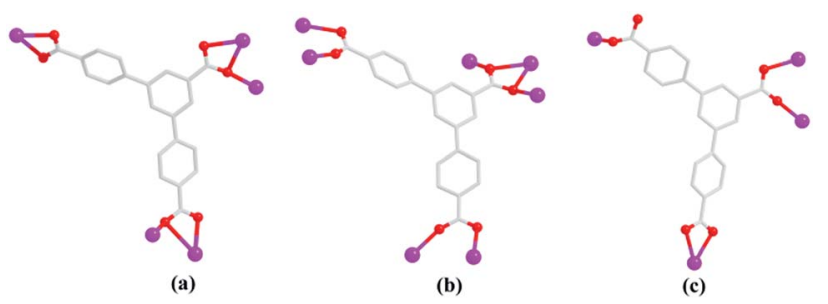

Scheme 2 The different coordination modes of 1 (a), 2 (b) and 3 (c). 

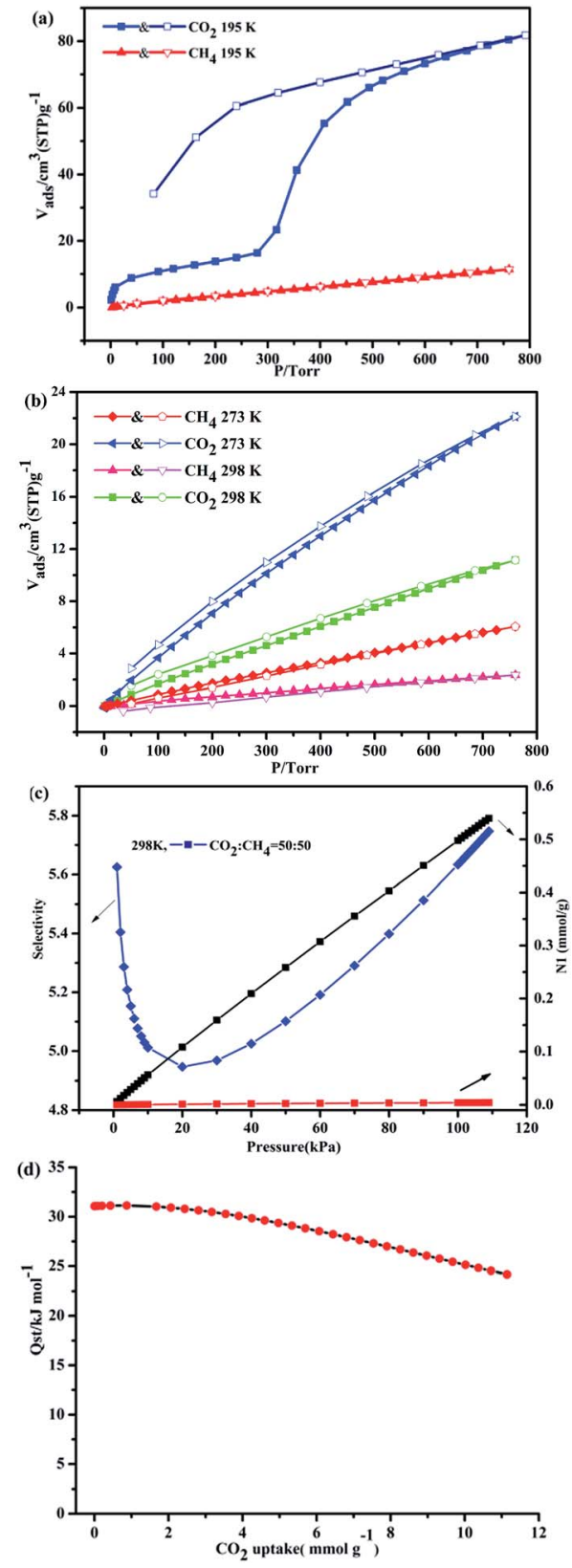

Fig. 7 (a) The adsorption isotherms of $1 \mathrm{a}\left(\mathrm{CO}_{2}\right.$ and $\left.\mathrm{CH}_{4}\right)$ at $195 \mathrm{~K}$. (b) The adsorption isotherms of $\mathrm{CO}_{2}$ and $\mathrm{CH}_{4}$ at 273 and $298 \mathrm{~K}$. (c) IAST adsorption selectivity of 1 a for equimolar mixtures of $\mathrm{CO}_{2}$ and $\mathrm{CH}_{4}$ at $298 \mathrm{~K}$. (d) Isosteric heat of $\mathrm{CO}_{2}$ adsorption for $1 \mathrm{a}$ by the virial equation from the adsorption isotherms at 273 and $298 \mathrm{~K}$.

uptake (11.39 $\left.\mathrm{cm}^{3} \mathrm{~g}^{-1}, 0.8 \mathrm{wt} \%\right)$. Such dynamic behaviors of layers are responsible for adsorption-induced gate-opening effects in MOF materials, which is associated with the flexibility of the frameworks. Thus, the activated sample of $\mathbf{1 a}$ appears to be the semi-closed form, and then undergoes the structural transformation to the open or as-synthesized form once the material obtains sufficient energy from gas adsorbate molecules to overcome energy barrier. ${ }^{17,18}$ Meanwhile, there is a marked broad hysteresis, confirming that the adsorbed $\mathrm{CO}_{2}$ is not immediately released on reducing the external pressure and is thus trapped

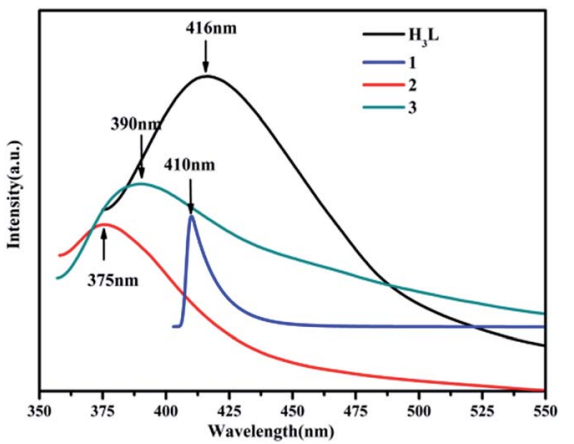

Fig. 8 Luminescent emission spectra of the free ligand $\mathrm{H}_{3} \mathrm{~L}$ (black), 1 (blue), 2 (red), and 3 (green) in the solid state at room temperature.

within the framework at very low pressures. The possible reason for the stepwise and hysteretic sorption isotherms of the material is related to the framework of 1a with the shrunken pores, and the host structure may expand above the gate opening pressure, which should be another typical example of the breathing MOFs. ${ }^{19}$ Such adsorption selectivity is also more evident at high temperatures. The $\mathrm{CO}_{2}$ uptake are $22.12 \mathrm{~cm}^{3} \mathrm{~g}^{-1}(4.31 \mathrm{wt} \%)$ at $273 \mathrm{~K}$ and $11.14 \mathrm{~cm}^{3} \mathrm{~g}^{-1}(2.21 \mathrm{wt} \%)$ at $298 \mathrm{~K}$ and 1 bar. Meanwhile, the $\mathrm{CH}_{4}$ uptakes are $6.0 \mathrm{~cm}^{3} \mathrm{~g}^{-1}(0.41 \mathrm{wt} \%)$ at $273 \mathrm{~K}$ and $2.37(0.17 \mathrm{wt} \%)$ at $298 \mathrm{~K}$ and $1 \mathrm{bar}$ (Fig. $7 \mathrm{~b})$.

Most interestingly, the examination of $\mathrm{CO}_{2}$ and $\mathrm{CH}_{4}$ sorption reveals that there is indeed existence of selectivity for respective sorbate molecules at different temperature. 1a shows high adsorption selectivity for $\mathrm{CO}_{2} / \mathrm{CH}_{4}$ at $298 \mathrm{~K}$, as shown in Fig. 7c. The adsorption selectivities are calculated via the ideal adsorption solution theory (IAST) ${ }^{\mathbf{2 0}-22}$ (Fig. S7, ESI $\dagger$ ). For an equimolar mixture, the $\mathrm{CO}_{2} / \mathrm{CH}_{4}$ selectivity is estimated as 5.6 at $298 \mathrm{~K}$. The isosteric heat $\left(Q_{\mathrm{st}}\right)$ of $\mathrm{CO}_{2}$ adsorption was calculated by the virial equation from the sorption isotherms at $298 \mathrm{~K}$. At initial coverage, $Q_{\mathrm{st}}$ start at $30.0 \mathrm{~kJ} \mathrm{~mol}^{-1}$, however, as the $\mathrm{CO}_{2}$ uptakes rise up to $11.16 \mathrm{mmol} \mathrm{g}^{-1}$, the $Q_{\text {st }}$ reaches to $24.1 \mathrm{~kJ} \mathrm{~mol}^{-1}$ (Fig. 7d). This value is superior to those MOFs decorated by typical active site such as Lewis basic sites (LBSs) and OMSs, for example $\mathrm{Cu}(\mathrm{bcppm})\left(29 \mathrm{~kJ} \mathrm{~mol}^{-1}\right){ }^{23}$ PCN-88 (27 $\left.\mathrm{kJ} \mathrm{mol}^{-1}\right){ }^{24}$ PCN-16 (22.5 $\mathrm{kJ} \mathrm{mol}^{-1}$ ) and Zn-MOF-74 (30 $\left.\mathrm{kJ} \mathrm{mol}^{-1}\right),{ }^{25}$ but much lower than those of some high polarity functionalized MOFs, such as CuBTTri-en $\left(80 \mathrm{~kJ} \mathrm{~mol}{ }^{-1}\right){ }^{26}$ MIL-100 (60 kJ mol $\left.{ }^{-1}\right)$, and MIL-101 (45 kJ mol${ }^{-1}$ ). ${ }^{27}$ The high enthalpies of $\mathrm{CO}_{2}$ enthalpies is mainly due to that the frameworks owns highly polar and specific interactions with $\mathrm{CO}_{2}$ because of its large quadrupole moment. Overall, this study provided theoretical prediction in $\mathrm{CO}_{2}$ capture and the fact that $1 \mathrm{a}$ has high selectivity of $\mathrm{CO}_{2}$, indicating that this material may be a promising adsorbent in the biogas treatment and natural gas clean up.

\subsection{Luminescence properties}

MOFs including $\mathrm{d}^{10}$ ions have been become the potential fluorescent materials in the optical field. ${ }^{28}$ Thus, the solid-state luminescence properties of the three MOFs and $\mathrm{H}_{3} \mathrm{~L}$ ligand were studied at room temperature (Fig. 8). The maximum 
emission peaks of the free $\mathrm{H}_{3} \mathrm{~L}$ ligand and 1-3 are observed at $\sim 416 \mathrm{~nm}$ for $\mathrm{H}_{3} \mathrm{~L}$ ligand $\left(\lambda_{\mathrm{ex}}=356 \mathrm{~nm}\right), \sim 410 \mathrm{~nm}$ for $1\left(\lambda_{\mathrm{ex}}=\right.$ $350 \mathrm{~nm}), \sim 375 \mathrm{~nm}$ for $2\left(\lambda_{\mathrm{ex}}=338 \mathrm{~nm}\right)$ and $\sim 390 \mathrm{~nm}$ for $3\left(\lambda_{\mathrm{ex}}=\right.$ $337 \mathrm{~nm})$, respectively. The maximum emissions of 2 and 3 are obviously blue shifted compared to those of $\mathrm{H}_{3} \mathrm{~L}$ ligand, which may arise from ligand-to-metal charge transfer (LMCT). Furthermore, the luminescence of $\mathbf{1}$ is similar to that of the free ligand, which is probably attributed to the intraligand transitions modified by metal coordination. ${ }^{29}$

\section{Conclusion}

In summary, three new luminescent MOFs including Cd(II) ions have been successfully assembled via a symmetrical tricarboxylate $\mathrm{H}_{3} \mathrm{~L}$ ligand. Because of the reactions in different solvent systems, $\mathrm{L}^{3-} / \mathrm{HL}^{2-}$ in 1-3 show the different coordination modes to form various SBUs in the final structures. Interestingly, complex 1 possesses two 1D open channels with different shapes. More importantly, the desolvated framework 1a displays permanent porosity with suitable pore size, which affords $\mathrm{CO}_{2}$ loading and selective capture for $\mathrm{CO}_{2}$ over $\mathrm{CH}_{4}$ at $273 \mathrm{~K}$. Herein, this work indicates that the unique structures and gas selectivity for $\mathrm{CO}_{2}$ may draw attention to the fabrication of functional MOF materials.

\section{Conflicts of interest}

There are no conflicts to declare.

\section{Acknowledgements}

We are grateful for financial support from the NSFC (21531007, 21371142, and 21201139), NSF of Shaanxi Province (2017KJXX59), the China Postdoctoral Science Foundation (2016M600807, and 2017T100765), and the Postdoctoral Science Foundation of Northwest University (334100049).

\section{Notes and references}

1 (a) H. Furukawa, K. E. Cordova, M. O'Keeffe and O. M. Yaghi, Science, 2013, 341, 1230444; (b) Y. Cui, B. Li, H. He, W. Zhou, B. Chen and G. Qian, Acc. Chem. Res., 2016, 49, 483-493; (c) G. Férey, Chem. Soc. Rev., 2008, 37, 191-214; (d) Y. Wu, G.-P. Yang, Y. Zhao, W.-P. Wu, B. Liu and Y.-Y. Wang, Dalton Trans., 2015, 44, 3271-3277; (e) M. Mon, J. Ferrando-Soria, T. Grancha, F. R. Fortea-Pérez, J. Gascon, A. Leyva-Pérez, D. Armentano and E. Pardo, J. Am. Chem. Soc., 2016, 138, 7864-7867.

2 (a) A. C. McKinlay, R. E. Morris, P. Horcajada, G. Férey, R. Gref, P. Couvreur and C. Serre, Angew. Chem., Int. Ed., 2010, 49, 6260-6266; (b) S. Horike, D. Umeyama and S. Kitagawa, Acc. Chem. Res., 2013, 46, 2376-2384; (c) J.-R. Li, J. Sculley and H.-C. Zhou, Chem. Rev., 2012, 112, 869-932; (d) T. Grancha, J. Ferrando-Soria, M. Castellano, M. Julve, J. Pasán, D. Armentanoc and E. Pardo, Chem. Commun., 2014, 50, 7569-7585.
3 Y. Inokuma, T. Arai and M. Fujita, Nat. Chem., 2010, 2, 780783.

4 (a) A. P. Côté, A. I. Benin, N. W. Ockwig, M. O'Keeffe, A. J. Matzger and O. M. Yaghi, Science, 2005, 310, 11661170; (b) A. G. Slater and A. I. Cooper, Science, 2015, 348, 8075 .

5 (a) D. Alezi, A. M. P. Peedikakkal, Ł. J. Weseliński, V. Guillerm, Y. Belmabkhout, A. J. Cairns, Z. Chen, Ł. Wojtas and M. Eddaoudi, J. Am. Chem. Soc., 2015, 137, 5421-5430; (b) S. Yang, A. J. Ramirez-Cuesta, R. Newby, V. Garcia-Sakai, P. Manuel, S. K. Callear, S. I. Campbell, C. C. Tang and M. Schröder, Nat. Chem., 2015, 7, 121-129; (c) R. Haldar, M. Inukai, S. Horike, K. Uemura, S. Kitagawa and T. K. Maji, Inorg. Chem., 2016, 55, 4166-4172.

6 J. Yu, L.-H. Xie, J.-R. Li, Y. Ma, J. M. Seminario and P. B. Balbuena, Chem. Rev., 2017, 117(14), 9674-9754.

7 (a) M.-H. Sun, S.-Z. Huang, L.-H. Chen, Y. Li, X.-Y. Yang, Z.-Y. Yuan and B.-L. Su, Chem. Soc. Rev., 2016, 45, 34793563; (b) D. Bradshaw, S. El-Hankari and L. LupicaSpagnolo, Chem. Soc. Rev., 2014, 43, 5431-5443; (c) H.-C. Zhou and S. Kitagawa, Chem. Soc. Rev., 2014, 43, 5415-5418; (d) T. T. Xu, C. F Xue, Z. L. Zhang and X. G. Hao, Prog. Chem., 2014, 26, 1924-1929.

8 (a) P.-Q. Liao, N.-Y. Huang, W.-X. Zhang, J.-P. Zhang and X.-M. Chen, Science, 2017, 356, 1193-1196; (b) M. J. Cliffe, E. Castillo-Martínez, Y. Wu, J. Lee, A. C. Forse, F. C. N. Firth, P. Z. Moghadam, D. Fairen-Jimenez, M. W. Gaultois, J. A. Hill, O. V. Magdysyuk, B. Slater, A. L. Goodwin and C. P. Grey, J. Am. Chem. Soc., 2017, 139, 5397-5404; (c) Y.-L. Huang, Y.-N. Gong, L. Jiang and T.-B. Lu, Chem. Commun., 2013, 49, 1753-1755; (d) Y.-N. Gong and T.-B. Lu, Chem. Commun., 2013, 49, 77117713.

9 (a) G. Ji, J. Liu, X. Gao, W. Sun, J. Wang, S. Zhao and Z. Liu, J. Mater. Chem. A, 2017, 5, 10200-10205; (b) H.-S. Lu, L.-L. Bai, W.-W. Xiong, P.-Z. Li, J.-F. Ding, G.-D. Zhang, T. Wu, Y.-L. Zhao, J. M. Lee, Y.-H. Yang, B.-Y. Geng and Q.-C. Zhang, Inorg. Chem., 2014, 53, 8529-8537; (c) Z.-J. Zhang, W. Lukasz and J. Z. Michael, Cryst. Growth Des., 2014, 14, 1526-1530.

10 (a) T. Grancha, X. Qu, M. Julve, J. Ferrando-Soria, D. Armentano and E. Pardo, Inorg. Chem., 2017, 56, 65516557; (b) S.-H. Huang, C.-H. Lin and W.-C. Wu, Angew. Chem., Int. Ed., 2009, 48, 6124-6127; (c) R. Chakrabarty, P. S. Mukherjee and P. J. Stang, Chem. Rev., 2011, 111, 6810-6918.

11 L.-L. Liu, C.-X. Yu, F.-J. Ma, Y.-R. Li, J.-J. Han, L. Lin and L.-F. Ma, Dalton Trans., 2015, 44, 1636-1645.

12 (a) D. Zhao, D. Yuan, D. Sun and H.-C. Zhou, J. Am. Chem. Soc., 2009, 131, 9186-9188; (b) Y.-W. Li, J. Xu, D.-C. Li, J.-M. Dou, H. Yan, T.-L. Hu and X.-H. Bu, Chem. Commun., 2015, 51, 14211-14214; (c) L. Qin, J.-S. Hu, Y.-Z. Li and H.-G. Zheng, Cryst. Growth Des., 2011, 11, 3115-3121; (d) M. Zhang, Q. Wang, Z. Lu, H. Liu, W. Liu and J. Bai, CrystEngComm, 2014, 16, 6287-6290.

13 (a) T. M. McDonald, W. R. Lee, J. A. Mason, B. M. Wiers, C. S. Hong and J. R. Long, J. Am. Chem. Soc., 2012, 134, 
7056-7065; (b) Y. He, S. Xiang, Z. Zhang, S. Xiong, F. R. Fronczek, R. Krishna, M. O'Keeffe and B. Chen, Chem. Commun., 2012, 48, 10856-10858; (c) W.-M. Chen, X.-L. Meng, G.-L. Zhuang, Z. Wang, M. Kurmoo, Q.-Q. Zhao, X.-P. Wang, B. Shan, C.-H. Tung and D. Sun, J. Mater. Chem. A, 2017, 5, 13079-13085.

14 (a) O. V. Dolomanov, L. J. Bourhis, R. J. Gildea, J. A. K. Howard and H. Puschmann, J. Appl. Crystallogr., 2009, 42, 339-341; (b) G. M. Sheldrick, Acta Crystallogr., Sect. C: Struct. Chem., 2015, 71, 3-8.

15 A. L. Spek, J. Appl. Crystallogr., 2003, 36, 7-13.

16 B. Liu, R. Zhao, G. Yang, L. Hou, Y.-Y. Wang and Q.-Z. Shi, CrystEngComm, 2013, 15, 2057-2060.

17 (a) C.-S. Liu, Z.-H. Zhang, M. Chen, H. Zhao, F.-H. Duan, D.-M. Chen, M.-H. Wang, S. Zhang and M. Du, Chem. Commun., 2017, 53, 3941-3944; (b) Q. Chen, Y. Ma, W. Song, Z. Chang, J.-R. Li, J. Zhang, H.-W. Sun, P. Balbuena and X.-H. Bu, Inorg. Chem., 2017, 56, 26142620; (c) Z. Shi, L. Qin and H. G. Zheng, Dalton Trans., 2017, 46, 4589-4594; (d) S. Horike, S. Shimomura and S. Kitagawa, Nat. Chem., 2009, 1, 695-704.

18 J. Duan, M. Higuchi, M. L. Foo, S. Horike, K. P. Rao and S. Kitagawa, Inorg. Chem., 2013, 52, 8244-8249.

19 G.-P. Li, G. Liu, Y.-Z. Li, L. Hou, Y.-Y. Wang and Z. Zhu, Inorg. Chem., 2016, 55, 3952-3959.

20 (a) D. Wang, B. Liu, S. Yao, T. Wang, G. Li, Q. Huo and Y. Liu, Chem. Commun., 2015, 51, 15287-15289; (b) A. G. Wong-Foy, O. Lebel and A. J. Matzger, J. Am. Chem. Soc., 2007, 129, 15740-15741.
21 (a) T. Pham, K. A. Forrest, B. Tudor, S. K. Elsaidi, M. H. Mohamed, K. McLaughlin, C. R. Cioce, M. J. Zaworotko and B. Space, Langmuir, 2014, 30, 64546462; (b) Y.-L. Wu, J. Qian, G.-P. Yang, F. Yang, Y.-T. Liang, W.-Y. Zhang and Y.-Y. Wang, Inorg. Chem., 2017, 56, 908913.

22 Y. Xie, H. Yang, Z. U. Wang, Y. Liu, H.-C. Zhou and J.-R. Li, Chem. Commun., 2014, 50, 563-565.

23 J. Zhao, Y. Wang, W. Dong, Y. Wu, D. S. Li, B. Liu and Q. Zhang, Chem. Commun., 2015, 51, 9479-9482.

24 J.-R. Li, J. Yu, W. Lu, L.-B. Sun, J. Sculley, P. B. Balbuena and H.-C. Zhou, Nat. Commun., 2013, 4, 1-8.

25 J. M. Simmons, H. Wu, W. Zhou and T. Yildirim, Energy Environ. Sci., 2011, 4, 2177-2185.

26 H.-R. Fu, F. Wang and J. Zhang, Dalton Trans., 2015, 44, 2893-2896.

27 A. Santra and P. K. Bharadwaj, Cryst. Growth Des., 2014, 14, 1476-1485.

28 (a) L. Luo, K. Chen, Q. Liu, Y. Lu, T.-A. Okamura, G.-C. Lv, Y. Zhao and W.-Y. Sun, Cryst. Growth Des., 2013, 13, 23122321; (b) P. Lama and P. K. Bharadwaj, Cryst. Growth Des., 2011, 11, 5434-5440; (c) R. Singh and P. K. Bharadwaj, Cryst. Growth Des., 2013, 13, 3722-3733; (d) J. Qian, P. Yu and S. Huang, CrystEngComm, 2016, 18, 7955-7958; (e) Y. Zhang, J. Han and C. Liao, CrystEngComm, 2016, 18, 9026-9032.

29 B.-B. Kang, N. Wei and Z.-B. Han, $R S C A d v .$, 2015, 5, 16051611. 